\title{
Decrease in incidence of women treated in hospital for acute salpingitis in Sweden
}

\author{
LARS WESTRÖM \\ From the Institute of Obstetrics and Gynaecology, University of Lund, Lund, Sweden
}

SUMMARY Numbers of women discharged from hospital after being treated for acute salpingitis decreased by $40 \%$ in Sweden between 1974 and 1984 . Several factors argue that this decrease was real, rather than a shift from inpatient to outpatient treatment. (Outpatients here include those treated by general practitioners as well as at hospital outpatient clinics.) The decrease was nation wide and included all age groups. Repeat episodes of the disease decreased more than first episodes. The main reason for the decrease seems to be more strict attitudes to sexual relationships, especially in young people. Public and professional awareness of genital chlamydial infections was probably a contributing factor.

Acute salpingitis, which is synonymous with pelvic inflammatory disease (PID), is caused by microorganisms that ascend from the lower genital tract.' During the 1960 s and 1970 s $60-80 \%$ of cases of salpingitis in women aged under 25 were caused by sexually transmissible organisms, such as Neisseria gonorrhoeae and Chlamydia trachomatis. ${ }^{23}$

Reflecting the worldwide epidemic of sexually transmitted diseases (STDs), the incidence of PID has increased in most countries. ${ }^{4}$ Most women attending Swedish hospitals with PID are treated as inpatients, though a constant $20 \%$ are not. In Sweden the annual incidence of gonorrhoea peaked in 1970 and decreased appreciably thereafter. ${ }^{5}$ In hospitals in southern Sweden admissions for acute salpingitis increased to 1977 and then decreased. ${ }^{6}$ The present investigation was performed to verify a nationwide decrease in salpingitis in Sweden.

\section{Methods}

In early 1986 all 53 departments of gynaecology in Sweden were asked for the following information: numbers of women discharged from hospital after being treated for acute salpingitis in the years 1959, 1964,1969 , and yearly from 1974 (diagnoses were to include acute salpingitis (International Classification

Address for reprints: Dr Lars Weström, Institute of Obstetrics and Gynaecology, University of Lund, S 22185 Lund, Sweden

Accepted for publication 25 March 1987 of Diseases (9th revision) (ICD-9) number 61209 ), gonorrhoea associated salpingitis (098 11), and "unqualified" acute salpingitis (614 99) (before 1968 the ICD-8 numbers were 622,030 , and 623 respectively)); and any changes in geographical catchment area, reporting systems, or major administrative changes since 1959.

Demographic information on the female population of Sweden was obtained from Statistical abstracts of Sweden (annual reports). ${ }^{7}$ The detailed information for the city of Lund was obtained from the continuing study of acute salpingitis that has been undertaken since 1960 at the department of gynaecology in this city. Routine diagnostic tests for genital chlamydial infection started in Lund in 1977.

\section{Results}

Information on hospital discharge rates for PID was obtained from 40 of the 53 hospitals, which were evenly distributed throughout the population. Of the reporting hospitals, 16 were comparable in having unchanged geographical catchment regions and clinical routines since 1959, a further nine since 1964, nine more since 1969, and a final six since 1974. In 1974-84 the $16,25,34$, and 40 hospitals cared for about $30 \%$, $50 \%, 60 \%$, and $75 \%$, respectively, of the female population of Sweden. Their yearly discharge numbers for every fifth year from 1969 to 1984 are given in figure 1 . As can be seen, the numbers of patients with salpingitis treated in those hospitals increased to 1974 and showed a pronounced decrease after 1979. In the 


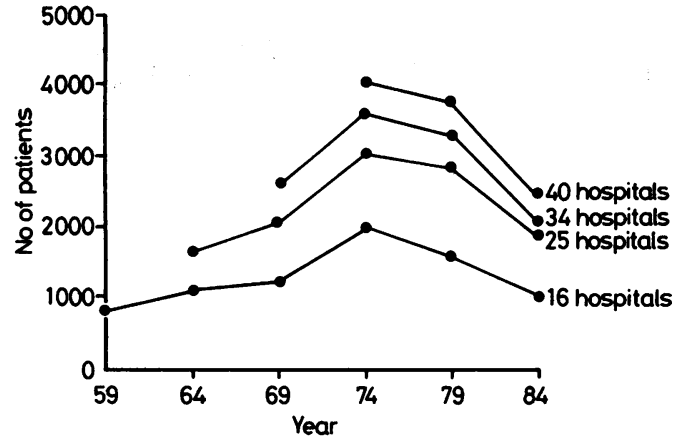

Fig 1 Numbers of women discharged from Swedish hospitals with comparable catchment regions and routines in 1959 and every fifth year after being treated for acute salpingitis.

40 hospitals that cared for about $75 \%$ of the total female population, the discharge numbers for PID fell from 4108 in 1974 to 2479 in 1984 a decrease of $40 \%$ of the 1974 figure.

Figure 2 gives the yearly discharge numbers for salpingitis from 1974 onwards from 25 hospitals providing such information. The yearly discharge numbers fell from 3306 in 1978 to 1745 in 1983 -a $47 \%$ decrease in four years. The number of women aged 15 to 24 (the high risk ages for PID)' increased slightly from 546500 in 1975 to 574700 in 1985.

Table 1 shows that the proportion of patients reported as having salpingitis associated with gonorrhoea peaked in 1969 at $25 \%$ of women with salpingitis, and decreased to about 5\% in 1984.

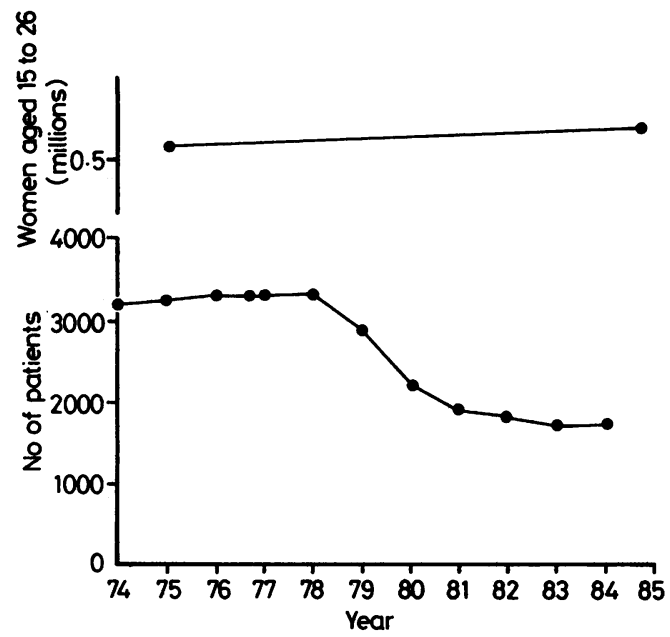

Fig 2 Yearly numbers of women treated for acute salpingitis and discharged from 25 hospitals in 1974-84, and numbers of women aged 15 to 24 in Sweden in 1975-85.
Table 1 Percentage of cases of salpingitis in Swedish hospitals diagnosed as being associated with gonorrhoea (ICD-9 098 11)

\begin{tabular}{|c|c|c|c|c|c|c|}
\hline \multirow{2}{*}{$\begin{array}{l}\text { No of } \\
\text { hospitals } \\
\text { reporting }\end{array}$} & \multicolumn{6}{|l|}{ Year } \\
\hline & 1959 & 1964 & 1969 & 1974 & 1979 & 1984 \\
\hline $\begin{array}{l}16 \\
25 \\
34 \\
40\end{array}$ & 24 & $\begin{array}{l}20 \\
20\end{array}$ & $\begin{array}{l}25 \\
22 \\
20\end{array}$ & $\begin{array}{l}15 \\
14 \\
15 \\
15\end{array}$ & $\begin{array}{l}13 \\
11 \\
14 \\
14\end{array}$ & $\begin{array}{l}5 \\
4 \\
5 \\
5\end{array}$ \\
\hline
\end{tabular}

Figure 3 shows the increase in salpingitis from 1969 to 77 despite the decrease in gonorrhoea after 1970 .

Table 2 shows the age specific incidence of women treated in hospital for laparoscopically verified acute salpingitis in the city of Lund. The table shows that: the decrease was proportionally the same in all age groups, gonorrhoea associated disease decreased more than both the total incidence and that of chlamydial salpingitis, and chlamydia associated salpingitis is also decreasing.

Figure 4 shows that during the last two five year periods, the decrease in incidence of repeat episodes of salpingitis (by a factor of 6.5) was greater than the decrease in first episodes of the disease (by a factor of 2).

Figure 5 shows the calculated cumulative numbers (per 1000 women in each of five birth cohorts) of first episodes of salpingitis based on the data from Lund. The calculated cumulative numbers of such infections per 1000 women by their 20th birthday showed small differences in the birth cohorts of 1945, 1950, 1955, and 1960 , whereas an appreciable decrease was seen in the 1965 birth cohort.

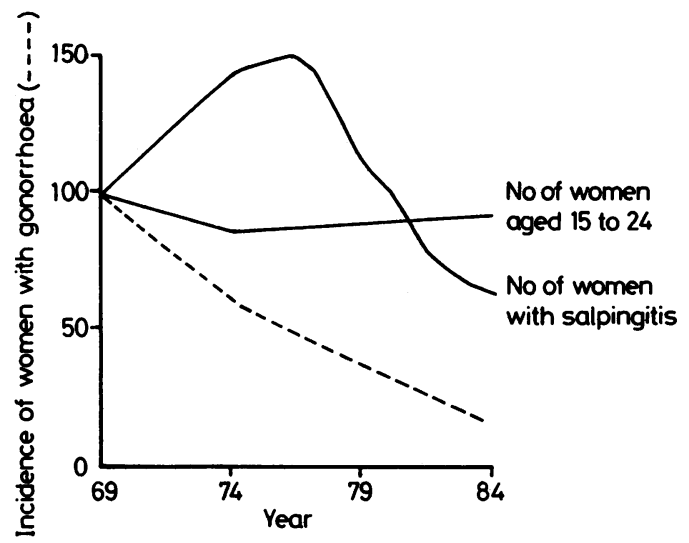

Fig 3 Incidence (per 100000 female population) of women with gonorrhoea compared with numbers of women aged 1524 and numbers of women discharged from hospital after treatment for PID in Sweden 1969-84, with the 1969 figures indexed 100. 
Table 2 Age specific mean incidence (per 1000 women and per year) of women treated in hospital for acute salpingitis, verified by laparoscopy, in Lund during five year periods 1960-84

\begin{tabular}{|c|c|c|c|c|c|c|}
\hline Age group & Type of salpingitis & $\begin{array}{l}1960-64 \\
(n=382)\end{array}$ & $\begin{array}{l}1965-69 \\
(n=478)\end{array}$ & $\begin{array}{l}1970-74 \\
(n=713)\end{array}$ & $\begin{array}{l}1975-79 \\
(n=708)\end{array}$ & $\begin{array}{l}1980-84 \\
(n=329)\end{array}$ \\
\hline $15-19$ & $\begin{array}{l}\text { Total } \\
\text { Gonococcal } \\
\text { Chlamydial }\end{array}$ & $\begin{array}{r}16.0 \\
9.0\end{array}$ & $\begin{array}{r}17.0 \\
7.7\end{array}$ & $\begin{array}{r}16.0 \\
3.9\end{array}$ & $\begin{array}{c}18 \cdot 2 \\
3 \cdot 3 \\
6 \cdot 2^{*}\end{array}$ & $\begin{array}{l}7 \cdot 8 \\
0.4 \\
5 \cdot 8\end{array}$ \\
\hline $20-24$ & $\begin{array}{l}\text { Total } \\
\text { Gonococcal } \\
\text { Chlamydial }\end{array}$ & $\begin{array}{l}7.5 \\
1.8\end{array}$ & $\begin{array}{r}10 \cdot 8 \\
2 \cdot 4\end{array}$ & $\begin{array}{r}14.2 \\
2.5\end{array}$ & $\begin{array}{c}12.6 \\
1.5 \\
6 \cdot 1^{*}\end{array}$ & $\begin{array}{l}5 \cdot 5 \\
0 \cdot 3 \\
3 \cdot 9\end{array}$ \\
\hline $25-29$ & $\begin{array}{l}\text { Total } \\
\text { Gonococcal } \\
\text { Chlamydial }\end{array}$ & $\begin{array}{l}3 \cdot 5 \\
0 \cdot 7\end{array}$ & $\begin{array}{l}4.5 \\
1.0\end{array}$ & $\begin{array}{l}8 \cdot 2 \\
1 \cdot 3\end{array}$ & $\begin{array}{l}6.5 \\
0.4 \\
2.8^{*}\end{array}$ & $\begin{array}{l}3 \cdot 2 \\
0.4 \\
1 \cdot 6\end{array}$ \\
\hline $30-34$ & $\begin{array}{l}\text { Total } \\
\text { Gonococcal } \\
\text { Chlamydial }\end{array}$ & $\begin{array}{l}3 \cdot 2 \\
0 \cdot 7\end{array}$ & $\begin{array}{l}2 \cdot 5 \\
0 \cdot 4\end{array}$ & $\begin{array}{l}4 \cdot 3 \\
0 \cdot 4\end{array}$ & $\begin{array}{l}5 \cdot 3 \\
0.5 \\
1 \cdot 4^{*}\end{array}$ & $\begin{array}{l}2.6 \\
0.2 \\
0.7\end{array}$ \\
\hline $35-39$ & $\begin{array}{l}\text { Total } \\
\text { Gonococcal } \\
\text { Chlamydial }\end{array}$ & $\begin{array}{l}1.9 \\
0.2\end{array}$ & $\begin{array}{l}1 \cdot 8 \\
0 \cdot 3\end{array}$ & $\begin{array}{l}1.7 \\
0.2\end{array}$ & $\begin{array}{l}3.4 \\
0.3 \\
0.2 *\end{array}$ & $\begin{array}{l}1.6 \\
0.2 \\
0.2\end{array}$ \\
\hline
\end{tabular}

*1977-9.

\section{Discussion}

In 1956 the Swedish parliament passed a law on a general public health care and insurance system. In essence, the community administers and cares for all hospitals. Hospital treatment is free to patients at their regional hospitals (that is, the hospital in the patient catchment region where they are registered). Outpatient treatment is provided at a low cost. These basic background factors were unchanged during the period covered by this analysis.

Because of urbanisation during the sixties and seventies, new hospitals were built and the patient

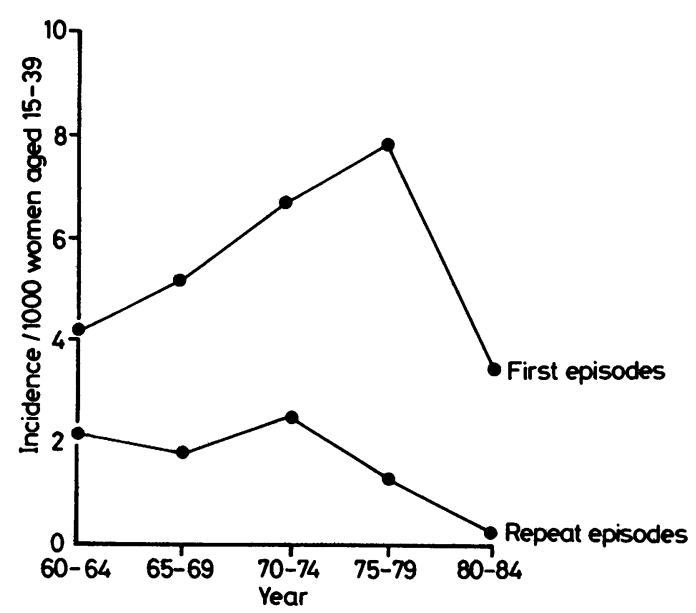

Fig 4 Mean incidence (per 1000 women aged 15 to 39 in Lund) of first or repeat episodes of acute salpingitis in five year periods from 1960. catchment regions of some old hospitals were changed. Such changes had to be accounted for in the analysis. Because patients are obliged to attend only their "own" hospitals, the comparisons were made between hospitals with unchanged patient catchment areas and clinical routines, which explains the distribution of reporting hospitals in figure 1 . All hospitals reported the same general pattern of increase, peak, and decrease irrespective of the proportions of laparoscopically verified diagnoses, whether they were in a rural or urban area, or their geographical location. The proportional peak in gonorrhoea associated PID coincided with the peak in uncomplicated gonorrhoea. ${ }^{5}$ The reported maximum figure of $25 \%$, however, was likely to be an underestimate because several hospitals reported no diagnoses of gonorrhoea associated PID (ICD-9 code 90811 ), probably by separating the diagnosis of gonorrhoea $(09800)$ from that of salpingitis (612 09). In urban hospitals reporting the diagnoses coded 09811 , peak rates of about $50 \%$ were reported in 1969 decreasing to about $5 \%$ in 1984 - a tenfold decrease.

It is noteworthy that the 1950 birth cohort of women, which showed the highest cumulative numbers of first episodes of PID (figure 5), passed through the peak of the STD epidemic in Sweden ${ }^{35}$ at the ages of 15 to 24-that is, at the high risk ages for salpingitis. ' In summary, the decrease in total hospital discharge numbers for salpingitis in Sweden was significant and nationwide.

In Sweden most women traditionally attend (or are referred to) hospitals if acute salpingitis is suspected or diagnosed. Most of these women are treated as inpatients, though about $20 \%$ are not. In Lund in $1960-77,79 \%$ of all women with PID were treated in 


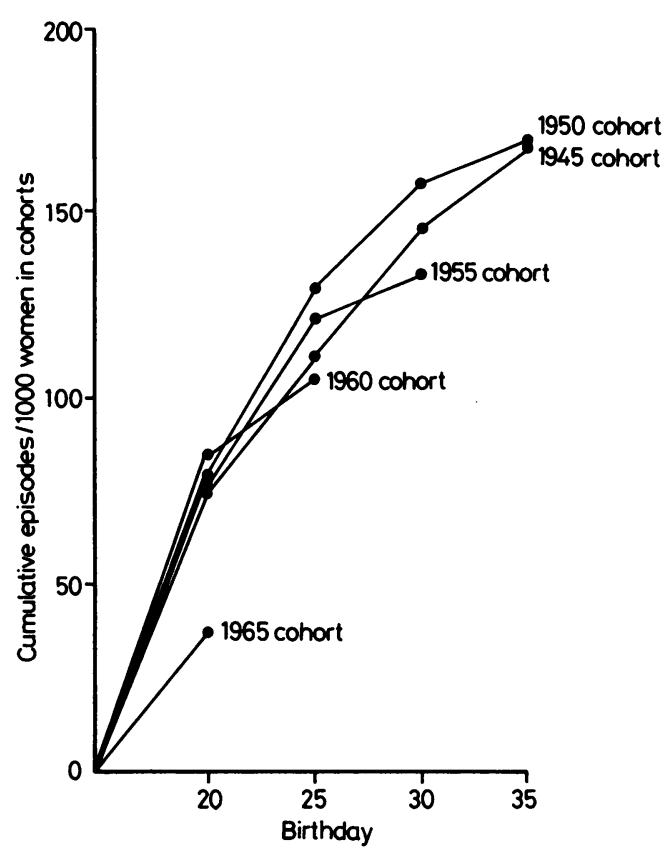

Fig 5 Calculated cumulative numbers of first episodes of acute salpingitis per 1000 women by age in the birth cohorts $1945,1950,1955,1960$, and 1965 in Lund.

the gynaecological department, and $21 \%$ as outpatients. ${ }^{8}$ On the other hand, outpatient guideline regimens for treating PID have been issued, ${ }^{9}$ and the clinically mild chlamydia associated PID is now proportionally more prevalent (table 2 )..$^{10}$ It is therefore reasonable to ask whether the decrease in hospital discharge rates reflects a real decrease or merely a shift from hospital to non-hospital treatment.

No information exists on the number of women with salpingitis currently treated outside hospitals. The following facts and observations, however, argue for a real decrease in the disease and against an appreciable increase in patients treated outside hospitals. (1) Uncomplicated gonorrhoea is decreasing. ${ }^{5}$ In young women in Lund the yearly incidence of genital chlamydial infections also decreased from $49 \cdot 2$ to $27 \cdot 1$ per 1000 women from 1970 to 1981." Thus the salpingitis producing STDs are decreasing. (2) If a larger proportion of clinically mild cases of PID were treated outside hospitals, a smaller proportion of mild cases might be expected in hospitals. This, however, was not the case. In Lund the proportion of clinically mild cases of salpingitis increased from $31 \%$ to $41 \%$ between 1975-79 and 1980-84 (table 3), when the total incidence of salpingitis was decreasing. (3) The total numbers of consultations (all patients) at non-specialist outpatient clinics (general practitioners) increased by $20 \%$ from 1979 to $1984,{ }^{12}$ whereas the hospital discharge numbers for PID decreased by $50 \%$ during the same period. (4) In view of the sequels of PID, ${ }^{13}$ there is now an increasing demand from both doctors and patients for laparoscopy to verify or exclude the diagnosis.

Although a small increase in outpatient treatment of salpingitis cannot be excluded, the conclusion must be that the decrease in acute salpingitis in Sweden is real. What factors may be behind this decrease? The primary and most obvious one seems to be that the STDs that produce salpingitis (gonorrhoea and chlamydial infection) are decreasing. That does not, however, answer the question. Instead we must ask why those STDs are decreasing.

Several factors that may account for the decrease in gonorrhoea since 1970 have been discussed. These include more effective treatment, more effective contact tracing, better education, the increased sale of condoms, and more tolerant attitudes about STDs in general. ${ }^{5}$ Many of those factors also apply, of course, to other STDs.

As for chlamydial infection, diagnostic facilities are now available nationwide. Intense educational campaigns about this infection have caused a general professional and public awareness, especially in young people. Information about STDs, including chlamydial infection, salpingitis, and infertility, is now given in schools to 12 to 14 year olds and is repeated later. In many urban areas, special youth clinics have been set up for, among other things, contraceptive advice. Special training courses on STDs have been given to midwives working in such clinics as well as in family planning units. The pronounced and appreciable decrease in repeat episodes of salpingitis is probably a result of gynaecologists' awareness of chlamydial PID and also the importance of examining sexual partners for this disease. Increased prescriptions of chlamydicidal drugs for "non-specific" genital infections may also have contributed to the decrease in chlamydial infection.

The most important factor for the decrease in gonorrhoea and chlamydial infection, however, seems to be a more "conservative" attitude to sex and changes of partners in young people during the past

Table 3 Mean yearly percentages of patients with laparoscopically mild or severe tubal infection (Lund during five year periods 1960-84)

\begin{tabular}{lll}
\hline Year & Mild & Severe \\
\hline $1960-64$ & $13 \cdot 2$ & $33 \cdot 9$ \\
$1965-69$ & $25 \cdot 8$ & $27 \cdot 7$ \\
$1970-74$ & $32 \cdot 0$ & $25 \cdot 5$ \\
$1975-79$ & $31 \cdot 3$ & $24 \cdot 0$ \\
$1980-84$ & $40 \cdot 9$ & 22.5 \\
\hline
\end{tabular}


decade. Although several sociological studies have been published about sexual knowledge, attitudes, and behaviour in young people during the past 20 years, it is difficult to document such changes. This is mainly because the studies have differed in their aims, study populations, and methodology. Some data seem to be comparable, however. In 1986, for example, $83 \%$ of men and $78 \%$ of women aged 18 to 19 reported that they had not had sexual intercourse during the month before the interview; ${ }^{14}$ in 1967 the corresponding figures were $36 \%$ for both sexes. ${ }^{15}$ In $198615 \%$ of men and $11 \%$ of women aged 18 to 24 reported having had more than one sexual partner during the previous six months; ${ }^{14}$ in $1971,{ }^{16}$ the corresponding figures for 18 to 19 year olds were $47 \%$ for men and $20 \%$ for women during the previous 12 months. ${ }^{16}$ Of married people, $2 \%$ reported having had extramarital sexual relationships during the previous six months in $1986,{ }^{14}$ whereas the same percentage had reported such relations during the previous month in $1967 . .^{\text {Is }}$

Brorsson stated "compared with earlier studies specifically aiming at studying sexual behaviour, this study (of knowledge about the acquired immune deficiency syndrome (AIDS)) showed significantly lower sexual activity". ${ }^{4}$ Professionals working in the field of STDs and with young people agree with this statement. Public awareness of AIDS might to some extent have changed sexual behaviour, at least during the past few years. ${ }^{14}$ This awareness, however, came too late to explain the decrease in gonorrhoea after 1970 , in chlamydial infections after 1980, and in salpingitis after 1978. Available information makes it likely that the most important reason for the decrease in STDs that produce salpingitis and in salpingitis was the combined effects of a decrease in the average number of partners and increased medical and public awareness of genital chlamydial infections. The observed decrease in PID in Sweden probably also predicts corresponding decreases in other countries.

\section{References}

1 Weström L, Mårdh P-A. Salpingitis. In: Holmes KK, Mårdh P-A,
Sparling PF, Wiesner PJ, eds. Sexually transmitted diseases. New York: McGraw Hill, 1984:615-32.

2 Mårdh P-A. An overview of infectious agents of salpingitis, their biology and recent advances in methods of detection. $\mathrm{Am} \mathrm{J}$ Obstet Gynecol 1980;138:933-51.

3 Ripa T, Forslin L, Danielsson D, Falk V. Frequency of gonococcal and chlamydial infections in patients with laparoscopically verified acute salpingitis in 1970 and 1980 . Epidemiological considerations. In: Mårdh P-A, Holmes KK, Oriel JD, Piot P, Schachter J, eds. Chlamydial infections. Amsterdam: Elsevier Biomedical Press, 1982:179-82.

4 Aral SO, Holmes KK. Epidemiology of sexually transmitted diseases. In: Holmes KK, Mårdh P-A, Sparling PF, Wiesner PJ, eds. Sexually transmitted diseases. New York: McGraw Hill, 1984:126-41.

5 Hansson H, Danielsson D. Epidemiology of sexually transmitted diseases in the Scandinavian countries. In: Mårdh P-A, Möller BR, Paavonen J, eds. Chlamydia trachomatis in genital and related infections. Stockholm: Almqvist \& Wiksell, 1982:150-6.

6 Weström L. Epidemiology of pelvic inflammatory disease. In: Ludwig H, Thomsen K, eds. Gynecology and obstetrics. Berlin, Heidelberg: Springer Verlag 1986:659-61.

7 National Central Bureau of Statistics. Statistical abstracts of Sweden. Stockholm: Liber distribution/Förlagsorder, 1978, 1983, 1984, and 1985.

8 Weström L, Mårdh P-A. Pelvic inflammatory disease. I. Epidemiology, diagnosis, clinical manifestations, and sequela. In: Holmes KK, Mårdh P-A, eds. International perspectives on sexually transmitted diseases. Impact on venereology, fertility, and maternal and infant morbidity. Washington DC: Hemisphere Publishing Company, 1982:235-58.

9 Centers for Disease Control. Sexually transmitted diseases treatment guidelines. MMWR 1982;31:43-4S.

10 Weström L, Mårdh P-A. Chlamydial salpingitis. Br Med Bull 1983;39:145-50.

11 Weström L, Svensson L, Wölner-Hansson P, Mårdh P-A. Chlamydial and gonococcal infection in a defined population of women. In: Mårdh P-A, Möller BR, Paavonen J, eds. Chlamydia trachomatis in genital and related infections. Stockholm: Almqvist \& Wiksell, 1982:157-62.

12 Anonymous. Fakta -86. Sjukvårds- och läkemedelsstatistik. Stockholm: LIF/RUFI, 1986:1-14.

13 Weström L. Reproductive events after acute salpingitis. Br J Clin Pract [Symp Suppl] 1982:suppl 17:17-20.

14 Brorsson B. Allmänhetens kunskaper $m m$ om LAV/HTLV-IIIinfektion och AIDS. Stockholm: Socialstyrelsen. Byrån för hälsoskydd (FAP 3). Socialstyrelsens Meddelandeblad No 21, 1986:1-49.

15 Anonymous. Statens offentliga utredningar. Stockholm: Om sexuallivet i Sverige. Esselte U SOU, 1969:2.

16 Eliasson R. Könsdifferenser $i$ sexuellt heteende och attityder till sexualiteten. Lund: Institute of Sociology, University of Lund, 1971:32 pp. Thesis. 